\title{
RECENT LAND USE AND LAND COVER CHANGE DYNAMICS IN THE GRAN CHACO AMERICANO
}

\author{
S. Banchero ${ }^{1}$, D. de Abelleyra ${ }^{1}$, S. R. Veron ${ }^{1}$, M. J. Mosciaro ${ }^{2}$, F. Arévalos ${ }^{3}$, J. N. Volante ${ }^{2}$ \\ ${ }^{1}$ Instituto de Clima y Agua, Instituto Nacional de Tecnología Agropecuaria (INTA) Hurlingham. Argentina \\ (banchero.santiago, deabelleyra.diego, veron.santiago)@inta.gob.ar \\ ${ }^{2}$ Estación Experimental Salta, Instituto Nacional de Tecnología Agropecuaria (INTA) Salta. Argentina \\ (mosciaro.jesus, volante.jose)@inta.gob.ar \\ ${ }^{3}$ Asociación Guyra Paraguay, Asunción. Paraguay - fabiana@ guyra.org.py
}

KEY WORDS: LULC, change dynamics, visual interpretation, machine learning

\begin{abstract}
:
Land transformation is one of the most significant human changes on the Earth's surface processes. Therefore, land use land cover time series are a key input for environmental monitoring, natural resources management, territorial planning enforcement at national scale. We here capitalize from the MapBiomas initiative to characterize land use land cover (LULC) change in the Gran Chaco between 2010 and 2017. Specifically we sought to a) quantify annual changes in the main LULC classes; b) identify the main LULC transitions and c) relate these transitions to current land use policies. Within the MapBiomas project, Landsat based annual maps depicting natural woody vegetation, natural herbaceous vegetation, dispersed natural vegetation, cropland, pastures, bare areas and water. We used Random Forest machine learning algorithms trained by samples produced by visual interpretation of high resolution images. Annual overall accuracy ranged from 0,73 to 0,74. Our results showed that, between 2010 and 2017, agriculture and pasture lands increased ca. 3.7 Mha while natural forestry decreased by $2.3 \mathrm{Mha}$. Transitions from forests to agriculture accounted for $1.14 \%$ of the overall deforestation while $86 \%$ was associated to pastures and natural herbaceous vegetation. In Argentina, forest loss occurred primarily (39\%) on areas non considered by the territorial planning Law, followed by medium (33\%), high (19\%) and low $(9 \%)$ conservation priority classes. These results illustrate the potential contribution of remote sensing to characterize complex human environmental interactions occurring over extended areas and timeframes.
\end{abstract}

\section{INTRODUCTION}

In Argentina, the information related to land use and land cover is characterized by its scarcity, diversity of scales, and poor data quality. This limits the provision of updated information to decision makers for designing environmental policies and generating knowledge about the factors that condition the sustainability of agro-ecosystems. Agricultural production data (acreage and yield) comes from subjective surveys with unknown accuracy level. This information is reported at department level and therefore hampers detailed and updated territorial synopsis on land use dynamics. Conversely, the environmental diversity of Argentina and its territorial extension are factors that hinder the possibilities to get updated and reliable information frequently enough.

The National Institute of Agricultural Technology (INTA) published the first map on land cover in Argentina using exploratory scale (Volante et al., 2010), being the first national map of this type. This cartography information was produced from field data and visual interpretation of Landsat and MODIS images, which involved great effort and time of work. In addition, an important effort was made to achieve a national legend compatible with other initiatives in the region (e.g. Uruguay). For this purpose, the FAO legend building system called Land Cover Classification System (Di Gregorio, 2005) was used. In 2013 an attempt was made to update it. Unfortunately though, this intention was unsuccessful due to fieldwork costs and interpretation time demand.

In Paraguay, efforts have been made to generate maps of land use and land cover in different time periods. Within the frame- work of the Project "Development of methodologies for monitoring carbon stored in forests for REDD+ in Paraguay", executed jointly by the Forest and Forest Products Research Institute of Japan (FFPRI) and the Forestry Engineering Career (CIF/FCA/UNA), a coverage map of the Republic of Paraguay was prepared for 2011. The methodology was based on the analysis and interpretation of Landsat 5 images, carrying out supervised classification and geoprocessing techniques. The minimum mapping unit was 100 hectares, due to existing information on the study area, time and available resources (FCA/CIF/FFPRI, 2013).

In this work, we present some results that MapBiomas Chaco Project for the Collection 1 that complete a time series cartography of land use and land cover between 2010 and 2017 using Earth Engine cloud computing technology to process Landsat data archive. The LULC maps were based on the random forest algorithm.

\subsection{Related Works}

For the Chaco region, there is an intiative developed by Faculty of Agnonomy (University of Buenos Aires), INTA and Red Agroforestal Chaco Argentina ${ }^{1}$ that generates annual maps of deforestation at $30 \mathrm{~m}$ resolution based on visual observation of Landsat imagery. In addition, Guyra generates deforestation maps for the Chaco region. Regional maps of land cover changes were developed also through the ONU-REDD project for land use planning in the Argentine Chaco.

\footnotetext{
${ }^{1}$ http://www.monitoreodesmonte.com.ar/
} 
There have been several regional mapping efforts the Paraguayan Chaco. Among the first initiatives is the map of Vegetation and Land Use of the Western Region of Paraguay in 1986/1987. It contains the description of the categories of Chaco vegetation defined according to the classification system used. This work was carried out in cooperation with CIF/FCA/UNA and the German Technical Cooperation (GTZ) (FCA/CIF/FFPRI, 2013).

Shortly thereafter, within the framework of the "Chaco Environmental Systems" Project, the Vegetation Map of the Paraguayan Chaco was prepared on a scale of 1:250,000 using Landsat TM images as inputs. This initiative was carried out in cooperation with the former Environmental Management Directorate (SSERMA/DOA) and the German Federal Institute for Geosciences and Natural Resources (BGR).

More recently, research led by the Department of Geography of Kansas State University generated annual coverage maps with the objective of analyzing the Land-cover change in the Paraguayan Chaco between 2000 and 2011, this study was carried out using MODIS images with a spatial resolution of $250 \mathrm{~m}$ (Caldas et al., 2015).

Likewise, Guyra Paraguay has published the Reports of deforestation in the Gran Chaco Americano area (which includes territories of Bolivia, Argentina and Paraguay) since 2010. The report includes information on deforestation in the Paraguayan Chaco, in terms of land use change, fires and floods. Documents containing tabular data as well as files containing spatial information ( $\mathrm{kmz}$ format, compatible with Google Earth) are available online. These products are generated on a monthly basis in order to monitor and compare the loss of forest cover and the behavioural pattern of the activity (REDD, 2016).

The main MapBiomas have been created for Brazil and it innovates by working in a network formed by NGOs, Universities, and private companies organized by biomes and crosscutting themes (Pasture, Agriculture, and Coastal Zones) (Azevedo Sr et al., 2018).

\section{DATA AND METHODS}

\subsection{Methodological description}

We here used satellite imagery from Landsat 5, 7, and 8 together with ground truth data determined by visual inspection of high-resolution imagery to train a random forest classifier and generate annual land cover maps of the Gran Chaco Americano from 2010 to 2017. This required: 1) Class definition; 2) Feature Space generation; 3) Collection of training samples; 4) Random Forest Classification; 5) Temporal and Spatial Filtering; 6) Validation (Figure 1).

2.1.1 Agreement of LULC class definition Eight classes were defined following the criteria of Land Cover Classification System LCSS-FAO (Di Gregorio, 2005) (Table 1). A protocol for the definition of the legend and criteria for visual interpretation was generated and discussed among interpreters of the project.

2.1.2 Generation of Landsat based Feature Space We used Google Earth Engine to process Top of Atmosphere (TOA) reflectance images from USGS Landsat 5 TM, Landsat 7 ETM+ and Landsat 8 OLI sensors intersecting the boundaries of the
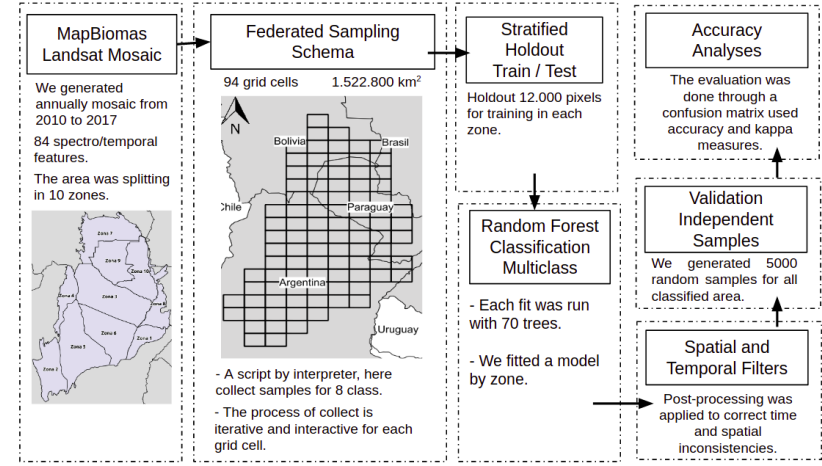

Figure 1. Methodological steps of Collection 1 to implement MapBiomas algorithms in the Google Earth Engine.

\begin{tabular}{ll}
\hline Level 1 & Level 2 \\
\hline 1. Natural Terrestrial & 1.1. Woody Natural Forestry \\
Vegetation & 1.2. Herbaceous \\
& 1.3. Scattered vegetation \\
2. Agricultural and Forestry & 2.1. Planted Forest \\
Areas & 2.2. Pasture \\
& 2.4. Agriculture \\
3. NonVegetable Areas & 3.1. NonVegetable Areas \\
5. Water Bodies & 5.1. Water Bodies \\
6. Non Observed & \\
\hline
\end{tabular}

Table 1. MapBiomas Chaco mapped classes follow LCSSFAO.

Chaco region between 2010 and 2017. Image availability with cloud covers less than 60 percent differed between between WRS tiles as well as between years. We additionally removed cloud, shadow, water or dark outliers pixels from each images using pixelQA information and the methodology proposed by Carson Stam and adapted by Ian Housman. Thus, the Feature Space included a) reflectance and thermal bands, b) spectral indexes, c) fractional cover obtained by spectral unmixing (Souza Jr, Barreto, 2000) and d) indexes derived from fractional cover.

For each of the above mentioned features we calculated 3 different composites based on 2 different types of image grouping. The first type was based on annual (january 1st - december 31st) information while the second on NDVI values (high: NDVI above 50 percentile, low: below 50 percentile). Thus, we reduced each of the 3 groups of images into a median, amplitude and standard deviation $30 \mathrm{~m}$ resolution composite on a per-pixel basis. From the resulting 225 composites -i.e. 25 variables calculated over 3 image sets by means of 3 metrics- we selected 84 as inputs for the classifications.

2.1.3 Generation of training samples We selected ground polygons over eight different cover types across the region: 1) woody natural forests, 2) woody crops, 3) herbaceous vegetation, 4) scatter vegetation, 5) pastures, 6) agriculture, 7) nonvegetated areas and 8 ) water bodies. We based our selection on the visual inspection of high-resolution imagery from Google Earth and Landsat images and MODIS NDVI time series. For this purpose we used the Code Editor and visual tools from GEE platform and the Google Earth software. False color LANDSAT median composites were generated specially for visual interpretation considering three periods along the growing season a) dry season composite (from Jun 1st to October 30th), b) wet season composite (from November 1st last year to April 1 st current year) and c) annual composite (from January 1 st to December 30th). The bands considered for visualization were 
Near infrared, Shortwave infrared 1 and Red. Thus, we manually picked locations where cover types were relatively homogeneous and remained unchanged over period considered (i.e. 2010-2017). To assure a representative sample, the region was gridded into 94 cells of $1^{\circ} \times 1.5^{\circ}$ (approx. $100 \times 150 \mathrm{~km}$ ) wherein each interpreter had to select a minimum of 10 polygons per class with and average size of 200 pixels, if possible. Finally, all the pixel located within the selected polygons were used as samples to train the classifier.

2.1.4 Random Forest Classification We applied a Random Forest classifier with 70 trees on each subregion (Figure 1). Random Forest is extensively used algorithm to classify remote sensing images and has been shown to provide higher accuracies and demand less processing time than other techniques. The algorithm was trained on data obtained by extracting the 84 values corresponding to the Feature Space from each of the training samples (i.e. pixels). To that end we first uploaded the Feature Space to GEE Assets.

2.1.5 Temporal and Spatial filtering Temporal and spatial filters based on MapBiomas procedure ((Souza, Azevedo, 2017)) were applied to remove classification inconsistencies. In particular transitions that are very infrequent were removed (for example Natural Woody Vegetation followed by pasture and then followed by Natural Woody Vegetation was changed to three years of Natural Woody Vegetation). The LULC maps of each subregion were integrated based on prevalence rules in order to generate the final Collection 1 map .

2.1.6 Validation Process We generated a completely independent set of validation samples. This validation set was based on statistical techniques to define sample points based on the extent and on the number of classes of all Chaco biome. A preliminary analysis was performed based on 5,000 pixel samples to each one of the years based on visual interpretation of Landsat data. Each sample was assign to and inspected by only one interpreter. This activity was based on a web application in Google Earth Engine over Code Editor, developed by INTA Team. The application allowed to classify a given pixel into one of the eight classes defined (Table 1), and an additional one for non-observed cases (i.e. lack of certainty). With this validation data we created a confusion matrix. The global accuracy was calculated for each year. Accuracy assessment analysis was conducted in the map Collection following the practices proposed by (Olofsson et al., 2014).

\section{RESULTS}

The Land use and land cover maps produced by this study presents an overall accuracy of more than 0.74 for all years (Table 2). The maps showed in the Figure 2 and Figure 3 correspond with the first and the last year of the time series, where we can see that main expansion occured in pasture class in the north area.

We analyzed some transitions from annual maps that corresponds to changes from natural woody vegetation to agriculture (Figure 4). This transition showed a reduction in the annual loss from natural woody vegetation to agriculture. On average the overall change between 2010 and 2017 was $1.14 \%$ for all the region. A different behavior we was observing at the transition from woody vegetation to herbaceous (Figure 5) and woody vegetation to pasture (Figure 6). Both transitions are bigger in area $(\leq 1.5 \mathrm{MHa}$ and $\leq 0.8 \mathrm{MHa}$ respectively) compared to transitions to agriculture ( $\leq 0.15 \mathrm{MHa})$. The average change for pasture was $5.25 \%$ and for herbaceous $5.2 \%$. Both transitions showed a smooth positive slope generate an increment in the area of change.

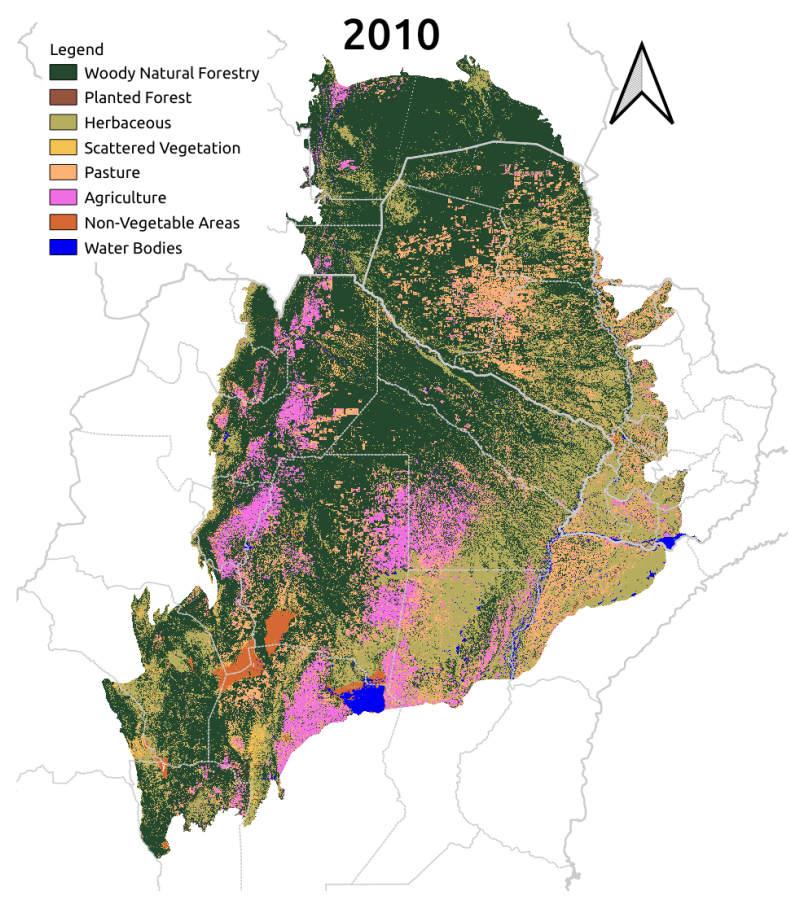

Figure 2. Map of the Gran Chaco for the initial years 2010 of the period evaluated by this study.

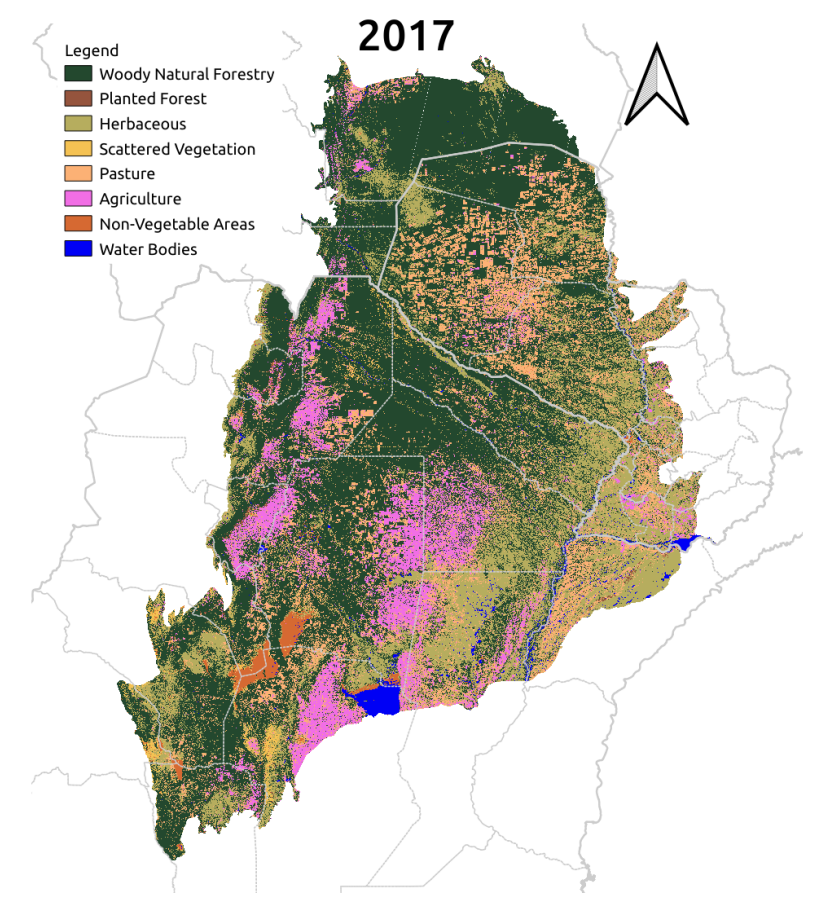

Figure 3. Map of the Gran Chaco for the last years 2017 of the period evaluated by this study.

\section{CONCLUSIONS}

In this work, we present some results derived from the maps of land use and land cover classification using remote sensing im- 


\begin{tabular}{ccccc}
\hline Year & Accuracy & Error & $\begin{array}{c}\text { Area } \\
\text { Disagreement }\end{array}$ & $\begin{array}{c}\text { Allocation } \\
\text { Disagreement }\end{array}$ \\
\hline 2010 & 0.744 & 0.255 & 0.085 & 0.169 \\
2011 & 0.743 & 0.257 & 0.072 & 0.184 \\
2012 & 0,738 & 0.261 & 0.077 & 0.183 \\
2013 & 0.742 & 0.257 & 0.085 & 0.172 \\
2014 & 0.743 & 0.256 & 0.081 & 0.175 \\
2015 & 0.740 & 0.260 & 0.075 & 0.184 \\
2016 & 0.735 & 0.264 & 0.075 & 0.188 \\
2017 & 0.742 & 0.257 & 0.077 & 0.180 \\
\hline
\end{tabular}

Table 2. The accuracy global for the level 2 of legend MapBiomas.

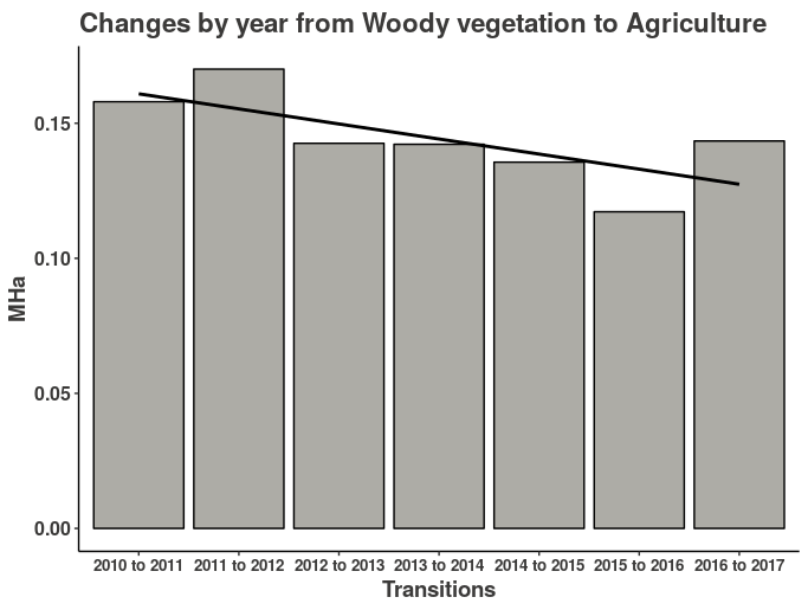

Figure 4. Annual transition between Woody vegetation and Agriculture

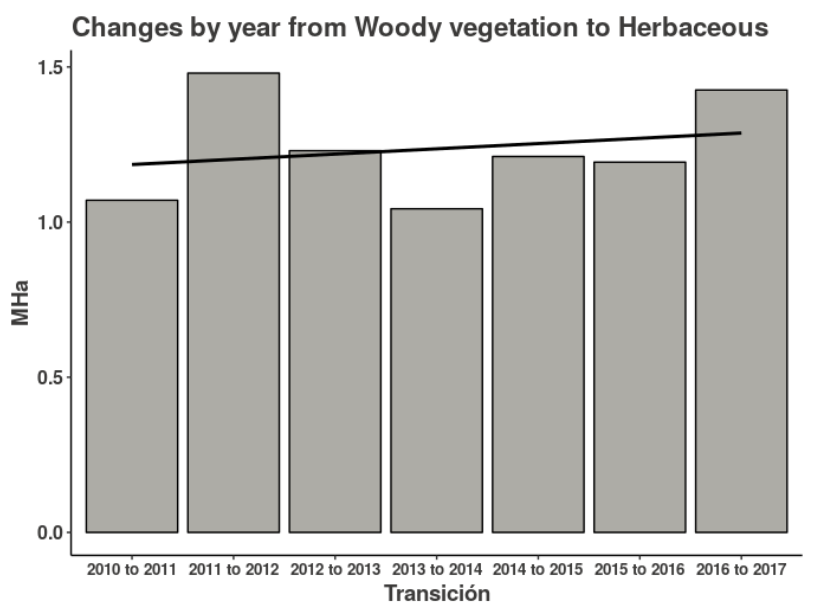

Figure 5. Annual transition between Woody vegetation and Herbaceous

agery. MapBiomas Chaco is a Decision Support System (SSD) and the land use land cover annual maps are a key input for environmental monitoring, natural resources management and territorial planning enforcement at national scale. We provide a systematic, consistent, objective, adaptive and reproducible methodology with relatively low costs. Is it also possible to generate knowledge associated with land use change drivers and consequences.

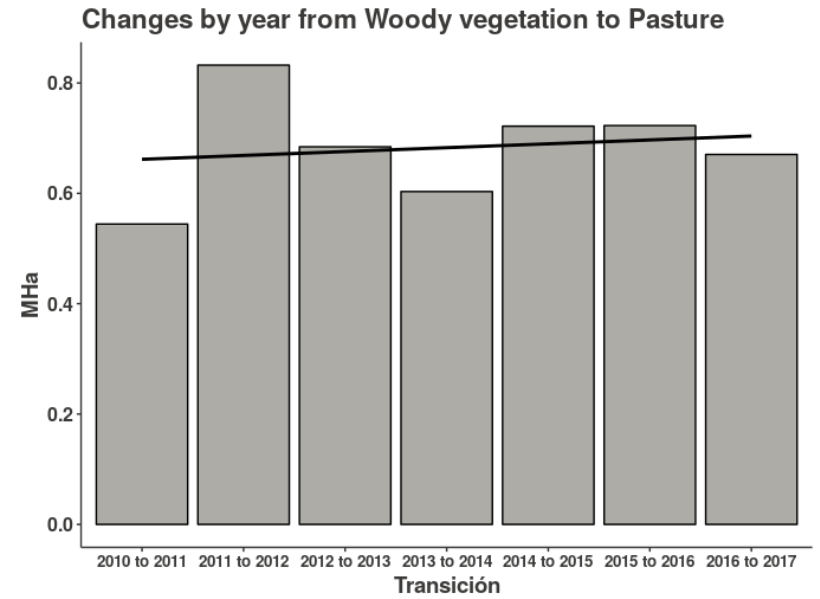

Figure 6. Annual transition between Woody vegetation and Pasture

\section{REFERENCES}

Azevedo Sr, T., Souza Jr, C., Shimbo, J., Alencar, A., 2018. Mapbiomas initiative: Mapping annual land cover and land use changes in brazil from 1985 to 2017. AGU Fall Meeting Abstracts.

Caldas, M. M., Goodin, D., Sherwood, S., Campos Krauer, J. M., Wisely, S. M., 2015. Land-cover change in the Paraguayan Chaco: 2000-2011. Journal of Land Use Science, 10(1), 1-18.

Di Gregorio, A., 2005. Land cover classification system: classification concepts and user manual: LCCS. 2, Food \& Agriculture Org.

FCA/CIF/FFPRI, 2013. Land cover map paraguay 2011. project "methodology for monitoring carbon stored in forests for redd+ in paraguay". Technical report, FCA/CIF/FFPRI, San Lorenzo, Paraguay.

Olofsson, P., Foody, G. M., Herold, M., Stehman, S. V., Woodcock, C. E., Wulder, M. A., 2014. Good practices for estimating area and assessing accuracy of land change. Remote Sensing of Environment, 148, 42-57.

REDD, P. O., 2016. Technical document for the elaboration of a map of historical deforestation in paraguay - period 2000 - 2015. Technical report, ONU - REDD Paraguay, Asunción, Paraguay.

Souza, C., Azevedo, T., 2017. MapBiomas General Handbook. MapBiomas: São Paulo, Brazil, 1-23.

Souza Jr, C., Barreto, P., 2000. An alternative approach for detecting and monitoring selectively logged forests in the Amazon. International Journal of Remote Sensing, 21(1), 173179.

Volante, J. N., Ayesa, J. A., Bubenik, K., Collado, A. D., Ferreyra, E., Lopez, C., Navarro de Rau, M. F., Pezzola, A., Puente, M., 2010. Cartografía de cobertura del suelo de la república argentina según el sistema de clasificación lccs-fao. año 2007-08. Congreso Argentino de la Ciencia del Suelo. 22. 2010 05-06 31-04, 31 de mayo a 4 de junio de 2010. Rosario, Santa Fé. $A R$. 